\title{
W. H. Beck
}

by Norma Beck, Saskatoon

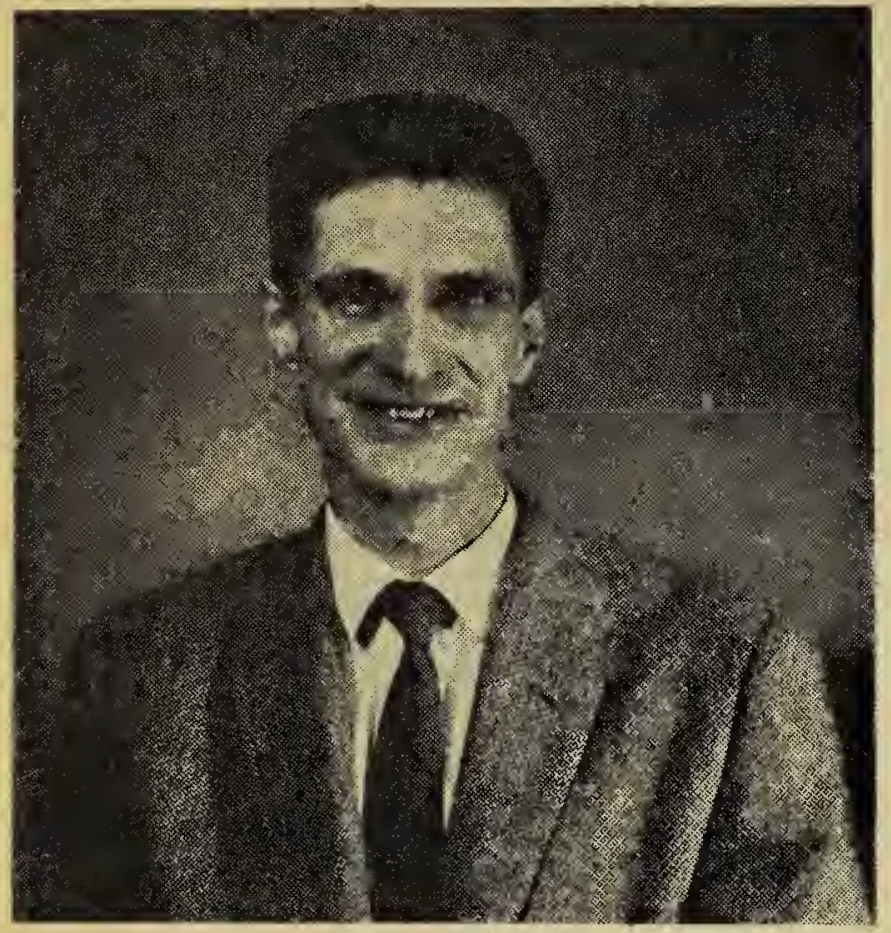

William Harvey Beck was born in 1927 in Yorkton, Saskatchewan. He evidenced no interest whatever in natural science until the age of two when he became passionately interested in investigating ant hills, bringing home caterpillars as pets, and keeping tadpoles in bottles. Our parents thought it best not to let him have a "killing bottle" to start his insect collection until he was almost five. Thereafter his bedroom was filled with mounted specimens. One of my cut-of-town boyfriends was once scared off by Harvey's invitation, "You may stay overnight and sleep in my bedroom if you don't mind bugs."

Mother once made Harvey a butterfly net by attaching a pillowslip to a broom handle, but as he weighed only forty pounds at the time, he found it a trifle unwieldy. On his next birthday, however, he received a real butterfly net, and from then on a familiar sight in Yorkton was a small boy pursuing moths with the rapt expression of Harpo Marx chasing a blonde across the tables.

Harvey was an criginal member of the Yorkton Natural History Society, and served on its first executive. He went on frequent field trips with the late Mrs. Isabel M. Priestly, and assisted at the birth of the first Blue $\mathbf{J a y}$ in 1942. It was mimeographed in those days, and we brightened its format by filling in the letters of the stenciled title, "The Blue Jay" with a blue pencil. Harvey owns on of the few complete sets of the Blu Jay.

In 1945 Harvey left Yorkton fo Saskatoon, where he majored in bio lcgy at the University of Saskat chewan. After two years at univer sity he attended the Provincia Nermal School at Moose Jaw, an his first school was at Pemmicas Portage near Cumberland House. On of his recollections of that eventfu year is being presented with a ver dead bear by an Indian as a gif (He and the bear lived amicabl. together until the spring thaw.)

Returning to the University 0 Saskatchewan, Harvey completed hi bachelor of arts degree in 1951 After teaching for a year in a rura school near Spiritwood, Saskatche wan, he became an assistant in bi ology at the University of Saskatche wan. While cataloguing the Univer sity mamal collection, he becam aware of the need for a guide $t$ Saskatchwan mammals, and for th past two years has been working to wards this end.

\section{MAMMALS OF SASKATCHEWAN}

Harvey Beck's bulletin on the mammals of Saskatchewan will be number 1 in the series of special publications on the flora and fauna of Saskatchewan to be published by the Saskatchewan Natural History Society. The Mammals of Saskatchewan will be an illustrated booklet listing the species of Saskatchewan mammals, with keys, brief descriptions of characteristics and indications of range. Price of the bulletin will be 50 cents, but a special pre-publication price of 25 cents has been set for any one ordering before July 1, 1958. Order your copy from Elmer Fox, 1053 Gladmer Park, Regina. 